\title{
Basic CFD model of heat pipe
}

\author{
Peter Hrabovský ${ }^{1,{ }^{*}}$, Zuzana Kolková ${ }^{1}$, Marián Mokrý ${ }^{1}$ and Patrik $\mathrm{Nemec}^{2}$ \\ ${ }^{1}$ University of Zilina - Reasearch Centre, Univerzitná 8215/1, 01026 Zilina, Slovakia \\ ${ }^{2}$ University of Zilina - Department of Power Energy, Univerzitná 8215/1, 01026 Zilina, Slovakia
}

\begin{abstract}
The article deals with the creation of the basis of the CFD model of the heat pipe, which is designed to simulate and show the predicted course of the work-fluid-activity within the heat pipe. This simulation is part of the study of the heat pipe device. This device, based on CFD simulation, can be constructed to describe the phenomena running inside the heat pipe based on real-world experimental measurements. A comparison of the CFD and the experimental model can explain the problems of areas and phenomena in the heat pipe. Based on this comparison, it is possible to optimize single device errors. The optimization transferred to the CFD model will show us how to solve problems and how to improve the experimental models of heat pipes.
\end{abstract}

\section{Introduction}

Heat pipes are now mainly used in refrigeration engineering, to remove heat from electrical components. They can be found mainly in computing, which is mounted on the processor (CPU, GPU, chipset ...) from which dissipates heat through active or passive cooler. The heat pipes are mainly used in the industry where it is necessary to comply with dustproof, air tightness, water tightness. From such a closed space can be removed heat by heat pipes [1].

Heat pipes are used in solar system for heating and heat transfer with heat exchangers. Heat pipes are devices that transfer heat efficiently. They can be used to transfer heat from the source at a higher energy potential for example built-in fireplaces in the home [2]. Of these, it is possible to capture the radiant heat component, which can be used for hot water or heating other rooms.

\section{Basis theory of experimental Heat Pipe}

We used a heat pipe to transfer heat from the heat source to the point of consumption of heat with high efficiency and low temperature difference. It is a sealed device in which the net substance (water) exist in the liquid and the gas phase at a pressure below atmospheric pressure (vacuum). Cleanliness of the working fluid is an important parameter for the efficiency of the heat pipe, in terms of heat transfer [3,4]. The actual heat pipe consists of evaporation, condensation, and the adiabatic section. In the evaporator the working fluid is

\footnotetext{
*Corresponding author: peter.hrabovsky@,rc.uniza.sk
} 
evaporated at a temperature below normal conditions. In the adiabatic section is not exchanged heat transfer through the ambient area, due to the isolation of a few working fluid to the wall of the heat pipe condensation film of condensed working fluid. In the condenser the vapour of working fluid condenses on the walls of the heat pipe, which transmit latent (condensing) heat through the walls of the heat pipe to the heat consumption point $[5,6,7]$. Figure 1 presents heat pipe model and heat pipe schema.

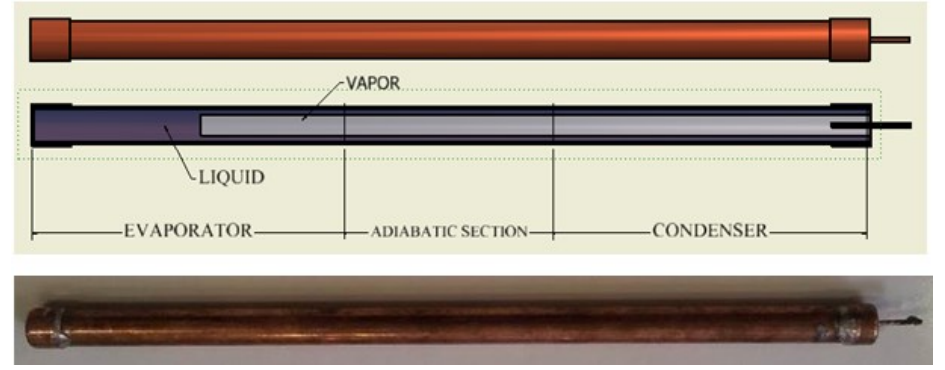

Fig. 1. Heat pipe.

\section{Description of Experimental Device Set}

A case situated in the upper part, is the part of a cooling device. It is connect to the cooling device, the cooling medium is water. The water circulates in a closed circuit between the cooling device and the case. In the cooling circuit included the safe cases, in which there are devices for measuring the temperature at entry and exit of water. In the circuit is included flow meter too that shows speed of flow of the refrigerant in a closed circuit. A case situated at the bottom part is the heating of the device. It is connected to the heating device, the working medium is water. In a closed heater circuit included thermocouples for temperature measurement inlet and outlet water from the case, flow meter for flow measurement. The circuit contents a valves that get disconnect the heater case when it is need for cooling with cold water, while avoiding the cooling of heating up the water in the heater circuit. Measured samples are mounted in the cases by caulked joints with seals, which are not being relaxed, possible leakage of cooling or heating of the working fluid. Figure 2 presents model of the gravity heat pipe and schema of measuring device.
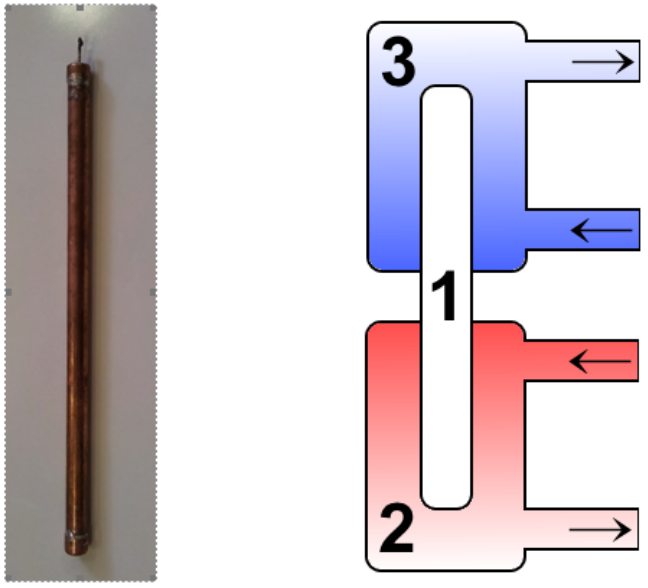

Fig. 2. Gravity heat pipe and scheme of experimental device 1 - heat pipe, 2 - heater, 3 - cooler. 


\section{Basic parameters of CFD Simulation by heat pipe}

The experiment was carried out in a mathematical simulation of CFD ANSYS.

The resulting mesh in the Figure 3 is a simplified model of polyhedral and has parameters 239302 cells, 1552487 faces, 1306224 nodes.

Individual volumes created appear cold water, hot water, copper rod, heat pipes filled with water-vapor - its thermal conductivity was changed in steps - 500, 1000, 2500, 5000, 10000, 15000, 20000, 25000, 30000, 40000, 45000, 50000.

Boundary conditions are the same as physical experiments (entered from physical experiment) - energy on, laminar flow - revealed by the Re $f(v, d)$, time-independent model.

Input parameters of cooling water - temperature $10{ }^{\circ} \mathrm{C}$, the mass flow rate $0.0287 \mathrm{~kg} \cdot \mathrm{s}^{-1}$. The outlet of cooling water was determined with parameter outflow. Input parameters of heater - temperature $80{ }^{\circ} \mathrm{C}$, the mass flow rate $0.0781 \mathrm{~kg} \cdot \mathrm{s}^{-1}$. The outlet of the heating water was determined with parameter outflow.

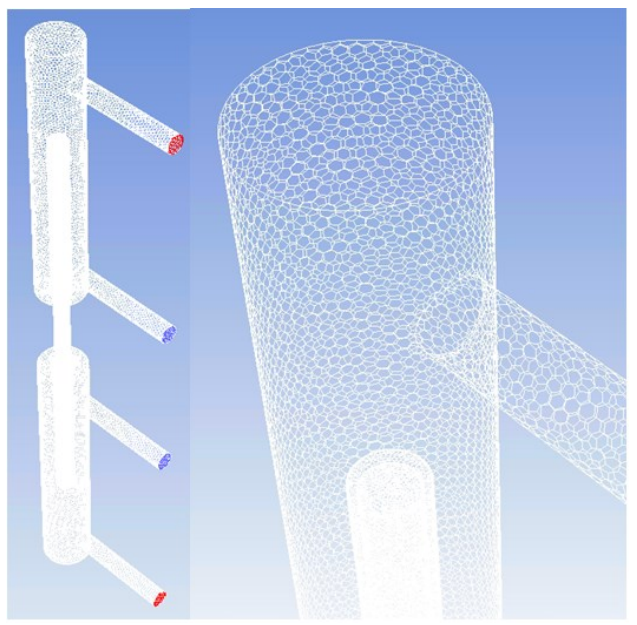

Fig. 3. Created mesh of CFD model of heat pipe.

Table 1. Result of simulation of heat pipe.

\begin{tabular}{|c|c|c|c|c|c|c|}
\hline $\begin{array}{c}\text { Thermal } \\
\text { coductivity }\end{array}$ & $\begin{array}{c}\text { In cold } \\
\text { water }\end{array}$ & $\begin{array}{c}\text { Out cold } \\
\text { water }\end{array}$ & $\begin{array}{c}\text { In cold } \\
\text { water }\end{array}$ & $\begin{array}{c}\text { Out cold } \\
\text { water }\end{array}$ & $\begin{array}{c}\text { Heat } \\
\text { capacity }\end{array}$ & Power \\
\hline$\left[\mathrm{W} \cdot \mathrm{m}^{-1} \cdot \mathrm{K}^{-1}\right]$ & {$[\mathrm{K}]$} & {$[\mathrm{K}]$} & {$\left[{ }^{\circ} \mathrm{C}\right]$} & {$\left[{ }^{\circ} \mathrm{C}\right]$} & {$\left[\mathrm{J}^{-1} \mathrm{~kg}^{-1} \cdot \mathrm{K}^{-1}\right]$} & {$[\mathrm{W}]$} \\
\hline 500 & 283.15 & 283.42 & 10 & 10.27 & 4197.62 & 32.92 \\
\hline 2500 & 283.15 & 284.30 & 10 & 11.15 & 4197.15 & 138.52 \\
\hline 5000 & 283.15 & 284.96 & 10 & 11.81 & 4196.80 & 217.71 \\
\hline 10000 & 283.15 & 285.75 & 10 & 12.60 & 4196.39 & 313.40 \\
\hline 15000 & 283.15 & 286.22 & 10 & 13.07 & 4196.14 & 369.55 \\
\hline 20000 & 283.15 & 286.53 & 10 & 13.38 & 4195.98 & 406.78 \\
\hline 25000 & 283.15 & 286.74 & 10 & 13.59 & 4195.87 & 433.04 \\
\hline 30000 & 283.15 & 286.90 & 10 & 13.75 & 4195.79 & 451.71 \\
\hline 40000 & 283.15 & 287.07 & 10 & 13.92 & 4195.70 & 472.79 \\
\hline 45000 & 283.15 & 287.10 & 10 & 13.95 & 4195.68 & 476.53 \\
\hline 50000 & 283.15 & 287.14 & 10 & 13.99 & 4195.67 & 480.26 \\
\hline
\end{tabular}


The results of simulation of heat pipe are shown in the picture Figure 4 . We can see, that the result of simulation are similarly as the result of physical model. When we use the water-vapor as the working fluid of heat pipe, the result of simulation are approaching to the result of physical model. We had changed one property of water-vapor, which is thermal conductivity.

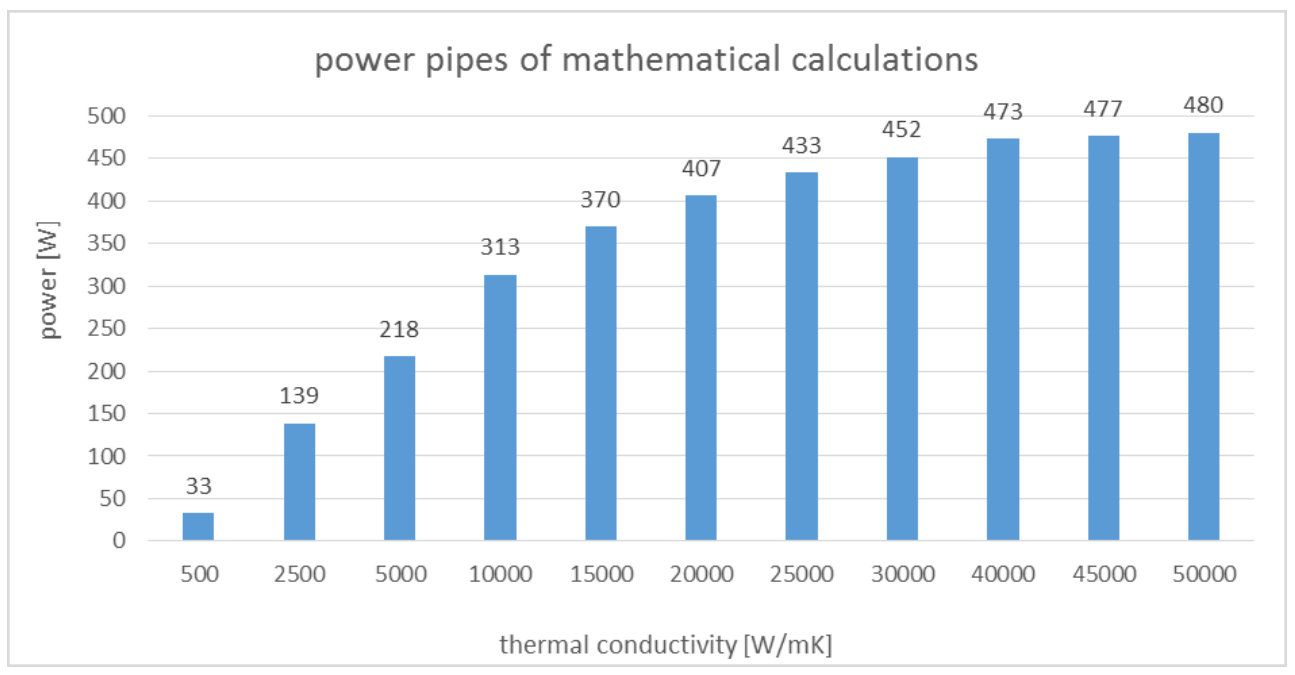

Fig. 4. Depend the power of thermal conductivity for CFD simulation.

In Figure 5 we can see progress of water-vapour, which has changeable property of thermal conductivity. Efficiency of heat transfer is directly depend on the value of thermal conductivity.

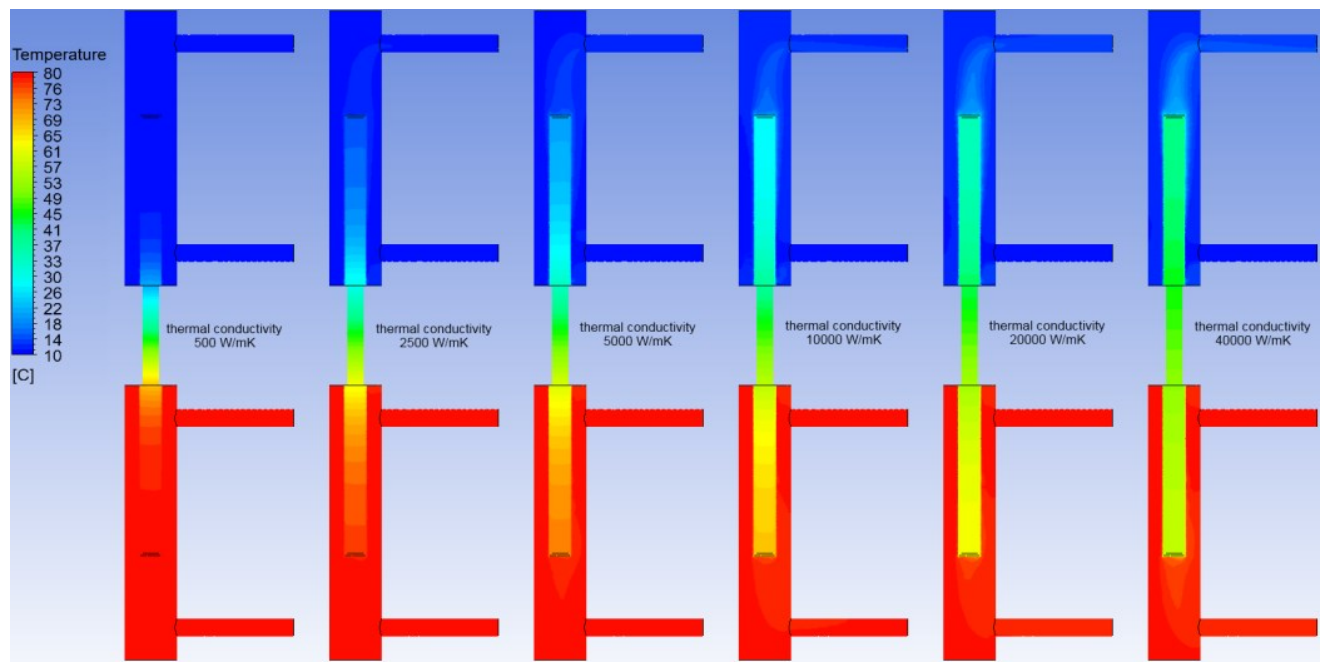

Fig. 5. Heat transfer at various values of thermal conductivity for CFD simulation of heat pipe.

In Table 1 are value of thermal conductivity, temperature of cooling water (in, out), heat capacity at temperature outer cooling water and power that the new material transferred in form of heat. 


\section{Conclusion}

This experiment was conducted for the heat transfer heat transfer basic research. The basic factor for this research is mathematical simulations in the Ansys program in Fluent. For the need to define the heat transfer process through the heat pipe in this program, it is necessary to examine the basic phenomena occurring in the heat pipe. Based on this analysis, it is possible to design a material with similar properties to the heat pipe. The newly created heat pipe replacement material will show us the basics of heat transfer through a heat pipe under different conditions. At this simulation, we determine a possibility of substitution of heat pipe with another material with changed of some parameter. We have approximated to real conditions of real heat pipe. This simulation is valid only for specific heat pipe, which is overwritten upper in section 3. This simulation is steady time. The new transient time simulation is in progress now.

Using simulation programs (such as the ANSYS CFD module) helps us to get an idea of the course of action activities of the action members and experimental phenomena, which can be optimized on the basis of the results obtained, thus reducing the problem of the experimental measurement.

This article forms the basis for creating a series of physical experiments based on CFDs and mathematical models to identify the unrecognized in the area of the use of heat pipes in their activities and in the ongoing phenomena.

The research is supported by the European Structural Fund - project ITMS 26220220048 (50\%).

The research is supported by project "Limits of Radiative and Convective Cooling through the Phase Changes of Working Fluid in Loop Thermosyphon", APVV-15-0778 (50\%).

\section{References}

1. R. Nosek, S. Gavlas, R. Lenhard, M. Malcho, V. Sedlak, S. Teie, AIP conference proceedings, 1917, (2017)

2. P. Ďurčansky, Š. Papučík, J. Jandačka, M. Holubčík, R. Nosek, The scientific world journal 2014, (2014)

3. J. Jandačka, J. Mičieta, M. Holubčík, R. Nosek, Energy \& fuels. 31, 3 (2017)

4. R. Lenhard, K. Kaduchová, Š. Papučík, J. Jandačka, EPJ Web of Conferences 67, (2014)

5. P. Ďurčanský, M. Patsch, J. Jandačka, AIP conference proceedings, 1745 (2016)

6. P. Pilát, M. Patsch, Š. Papučík, M. Vantúch, AIP Conference Proceedings, 1608, (2014)

7. R. Lenhard, M. Malcho, J. Jandačka, Heat transfer engineering, 40, 3 (2019) 